\title{
Electrostatic versus Nonelectrostatic Effects in DNA Sequence Discrimination by Divalent Ions $\mathrm{Mg}^{2+}$ and $\mathrm{Mn}^{2+}$
}

\author{
Iván Solt, ${ }^{\dagger, »}$ István Simon, ${ }^{\dagger}$ Attila G. Császár,,$\$$ and Monika Fuxreiter* ${ }^{*} \dagger$ \\ Institute of Enzymology, Biological Research Center, Hungarian Academy of Sciences, \\ H-1518 Budapest PO Box 7, Hungary, and Laboratory of Molecular Spectroscopy, Eötvös Loránd University, \\ H-1117 Budapest Pázmány Péter sétány 1/A, Hungary
}

Received: October 17, 2006; In Final Form: February 5, 2007

\begin{abstract}
$\mathrm{Mg}^{2+}$ and $\mathrm{Mn}^{2+}$ ions are critical to the functioning of phosphoryl transfer enzymes, such as restriction endonucleases. Although these ions play similar roles in the chemical steps, they govern substrate specificity via modulating sequence discrimination by up to a factor of $10^{5}$ with $\mathrm{Mg}^{2+}$ and only up to a factor of 10 with $\mathrm{Mn}^{2+}$. To explain whether such diversity originates in fundamental differences in the electronic structures of the nucleobase-hydrated-metal ion complexes, structures and interaction energies were determined at the density functional (DFT) and second-order Møller-Plesset (MP2) levels of theory. Although both metal ions favor identical binding sites, $\mathrm{Mn}^{2+}$ complexes exhibit greater distortions from the ideal octahedral geometry and larger variability than the corresponding $\mathrm{Mg}^{2+}$ systems. In inner-shell complexes, with direct contact between the metal and the nucleobase, $\mathrm{Mg}^{2+}$ is preferred over $\mathrm{Mn}^{2+}$ in the gas phase, due primarily to nonelectrostatic effects. The interaction energies of the two metal ions are more similar in the outer-shell complexes, likely due to reduced charge transfer between the hydrated metal ion and the base moieties. Inclusion of solvation effects can amplify the relative nucleobase preferences of $\mathrm{Mg}^{2+}$ and $\mathrm{Mn}^{2+}$, indicating that bulk hydration modulates the balance between electrostatic and nonelectrostatic terms. In most cases, the base substitutions in solution are facilitated more by $\mathrm{Mn}^{2+}$ than by $\mathrm{Mg}^{2+}$. Electrostatic properties of the environment were demonstrated to have a major influence on the nucleobase preferences of the two metal ions. Overall, quantum chemical calculations suggest that the contrasting selectivity of $\mathrm{Mg}^{2+}$ and $\mathrm{Mn}^{2+}$ cofactors toward nucleobases derives from the larger flexibility of the $\mathrm{Mn}^{2+}$ complexes accompanied by the excessive polarization and charge-transfer effects as well as less favorable solvation.
\end{abstract}

\section{Introduction}

Divalent metal ions are critical to the proper functioning of various biomolecules. These ions can assemble and stabilize protein structures ${ }^{1,2}$ and can induce complex formation with their substrates. ${ }^{3,4}$ Many enzymes utilize them as cofactors to facilitate chemical conversions. ${ }^{5-7}$ Divalent metal ions play a distinguished role in nucleic acid biochemistry. ${ }^{8}$ In the catalytic machinery of enzymatic phosphoryl transfer, they act as Lewis acids to reduce the accumulation of negative charge in the transition state. ${ }^{9-11}$ Divalent metal ions are crucial for folding of RNA as well as for the catalytic machinery of ribozymes. ${ }^{12}$ Magnesium and calcium ions were reported to interfere with the structure of DNA in a sequence specific manner that is dependent on the ion type as well. ${ }^{13} \mathrm{Mg}^{2+}$ ions primarily bind to phosphate groups of the DNA backbone via a solvent molecule in a so-called outer-shell mode. ${ }^{14,15}$ Divalent metal ions were also observed to penetrate into the grooves, ${ }^{16,17}$ where by crosslinking the base atoms of the opposite strands, they can modify the groove width and promote kinking of the DNA. Such sequence-specific structural changes can govern the interaction of drug molecules with DNA. ${ }^{8}$ For example, the selective binding of the antitumor antibiotics mythramycin ${ }^{18}$ is assisted by simultaneous coordination of $\mathrm{Mg}^{2+}$ ions to the minor groove of the Z-DNA and to the drug molecule.

* Corresponding author phone: (36-1)-279-3138; fax: (36-1)-466-5465; e-mail: monika@enzim.hu.

$\dagger$ Hungarian Academy of Sciences.

Eötvös Loránd University.
Out of the versatile roles of divalent metal ions in biochemistry, the present work has been motivated by the diversity of metal ion functions in restriction endonucleases. ${ }^{19}$ These enzymes protect prokaryotic organisms from invading phages by recognizing a $4-6$ base pair long palindromic sequence of the foreign DNA and catalyzing the scission of the backbone at a given position. In the presence of $\mathrm{Mg}^{2+}$ ions a remarkable substrate-specificity can be observed characterized by a binding constant $\left(K_{\mathrm{M}}\right)$ that is increased by 3 orders of magnitude and a reaction rate $\left(k_{\text {cat }}\right)$ that is decreased by 6 orders of magnitude upon a single base pair change in the cognate sequence. ${ }^{20,21}$ Such stringent sequence discrimination drops significantly with $\mathrm{Mn}^{2+}$ ions; ${ }^{22,23}$ for the EcoRV enzyme by a factor of $10^{5}$ when activities of the specific GATATC and the noncognate GTTATC sequence ${ }^{24}$ are compared. Furthermore, $\mathrm{Mn}^{2+}$ ions often promote "star activity", when a noncognate sequence differing by one base pair from the substrate sequence is processed. ${ }^{25,26} \mathrm{We}$ hypothesize that since the presence of divalent metal cations is often required for specific binding of DNA to restriction enzymes ${ }^{21,27-29}$ these metal ions can serve as "markers" of the sequence.

To probe this idea we investigated the selectivity of $\mathrm{Mg}^{2+}$ and $\mathrm{Mn}^{2+}$ ions toward nucleic acid bases. Although in proteinDNA complexes these ions are exquisitely coordinated to the scissile phosphate to facilitate phosphoryl-transfer, ${ }^{30,31}$ in free DNA they are attached to the base atoms as well. ${ }^{16,17,32}$ Such indirect interactions support sequence-specific structural ele- 


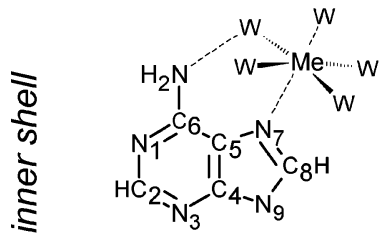

A-N7

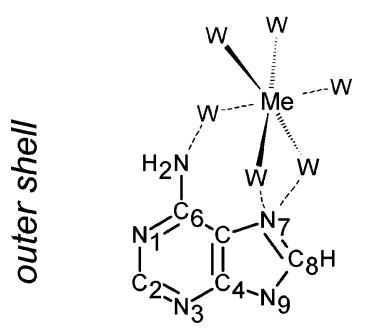

A-N7/N6

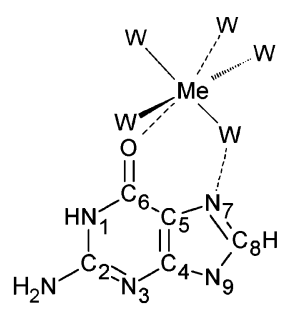

G-O6

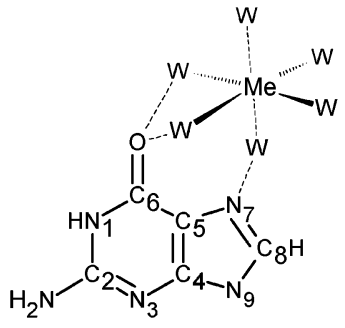

G-N7/O6<smiles></smiles>

$\mathrm{C}-\mathrm{O} 2$<smiles></smiles><smiles></smiles>

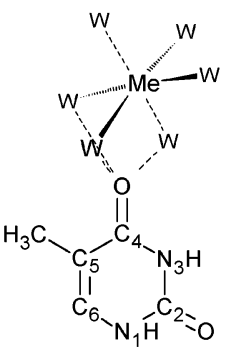

T-O4

Figure 1. Schematic representation of the inner- and outer-shell nucleobase complexes with $\mathrm{Mg}^{2+}$ and $\mathrm{Mn}^{2+}$ ions with the largest interaction energies. Me stands for the metal ions and $\mathrm{W}$ for the water molecules. The numbering of the base atoms shown on the figure is used throughout the paper. Hydrogen bonds are shown by dashed lines.

ments $^{8,13}$ and modulate the electrostatic properties of the surrounding nucleotides to enhance steric and electrostatic complementarity with the binding site of the protein. These metal-ion-dependent features can "label" the cognate DNA site and induce specific binding to the protein. Upon complex formation the divalent metal ions are either replaced by the protein residues or shifted to their final position at the active center. In contrast, the original metal ion positions serve to guide the protein to its specific site. Thus differences in metal ion preferences toward nucleobases can reveal the reasons for altered sequence discrimination by $\mathrm{Mg}^{2+}$ and $\mathrm{Mn}^{2+}$ ions.

Previous ab initio electronic structure calculations ${ }^{33}$ demonstrated that the metal ion preferences can differ even at a single base pair level: Guanine at the $\mathrm{N} 7$ position prefers $\mathrm{Zn}^{2+}$ over $\mathrm{Mg}^{2+}$ ions and their interaction energies deviate considerably due to the altered balance between the metal-base and metalwater interactions. A marked difference between the flexibility of the hydration shell of the two metal ions was also observed. Even in the case of a single guanine nucleobase, the diversity between the $\mathrm{Mg}^{2+}$ and $\mathrm{Zn}^{2+}$ binding could be explained based on differences in the electronic structure of the complexes of the two metal ions ${ }^{34}$ that cannot be captured by simple pairwise additive energy terms. In the gas phase the stability of tetra-, penta-, and hexahydrated $\mathrm{Mg}^{2+}$ complexes with guanine was shown to be related to the charge transfer between the two units. ${ }^{35}$ The importance of charge transfer and polarization contributions to $\mathrm{Mg}^{2+}-\mathrm{G}$ interactions was also demonstrated by taking the effect of bulk solvation into account. ${ }^{36}$

In spite of the biological importance of $\mathrm{Mn}^{2+}$ ions in DNA chemistry $^{37}$ the structural and electronic properties of hydrated $\mathrm{Mn}^{2+}$ ions in complexes formed with the four nucleobases have never been studied before. In this work both inner- and outershell forms (i.e., penta- or hexahydrated forms) have been investigated and the structural properties were compared to the corresponding $\mathrm{Mg}^{2+}$ complexes. Geometry optimizations were carried out for all possible coordination sites. Interaction energies were determined at the Møller-Plesset (MP2) ${ }^{38}$ level including basis set superposition error (BSSE) ${ }^{39,40}$ correction. We found that $\mathrm{Mn}^{2+}$ complexes, as compared to those of $\mathrm{Mg}^{2+}$ ions, are more flexible and can be characterized with smaller (negative) interaction energy. Differences between the interaction energies of the four nucleobases with the hydrated metal ions, however, vary for $\mathrm{Mg}^{2+}$ and $\mathrm{Mn}^{2+}$ reflecting altered selectivity of the two metal ions. Furthermore, differences in interaction energies obtained in the gas phase can be increased upon including the solvation effect. To understand this phenomenon in more detail, we partitioned the interaction energy in the gas phase according to the Natural Energy Decomposition Analysis (NEDA) ${ }^{41-43}$ scheme. We observed that the so-called nonelectrostatic, charge transfer and polarization terms vary remarkably for $\mathrm{Mg}^{2+}$ and $\mathrm{Mn}^{2+}$. The molecular factors identified in the present study can rationalize the altered sequence discrimination of the two metal ions.

Computational Details. Models. Inner- and outer- shell complexes of $\mathrm{Mg}^{2+}$ and $\mathrm{Mn}^{2+}$ with adenine (A), guanine (G), cytosine $(\mathrm{C})$, and thymine $(\mathrm{T})$ nucleobases were constructed using standard nucleobase structures within the GaussView $3.09^{44}$ program. Inner-shell complexes included a direct coordination between the metal ion and the nucleobase, i.e., contained a pentahydrated metal ion site. In the outer-shell complexes the interaction between the metal ion and the base was mediated by one or more water molecule(s); i.e., including a hexahydrated metal ion.

For inner-shell complexes, the following possible coordination sites were considered: $\mathrm{N} 1, \mathrm{~N} 3$, and $\mathrm{N} 7$ for $\mathrm{A}, \mathrm{O} 6$ and $\mathrm{N} 7$ for $\mathrm{G}, \mathrm{O} 2$ for $\mathrm{C}$, and $\mathrm{O} 2$ and $\mathrm{O} 4$ for $\mathrm{T}$ (see Figure 1 for nomenclature). In the case of outer-shell complexes, various coordination sites were studied at the Hartree-Fock $(\mathrm{HF})^{45-48}$ level using the $3-21 \mathrm{G}$ basis set ${ }^{49-51}$ and using density-functional theory $[\mathrm{DFT}(\mathrm{B} 3 \mathrm{LYP})]^{52-55}$ with the $6-311 \mathrm{G}^{* *}$ basis set. ${ }^{51,56}$ Only structures with the three lowest energies were included for further analysis: N6/N7, N1 and N3 for A, N7/O6 for G, $\mathrm{N} 1 / \mathrm{O} 2$ for $\mathrm{C}$, and $\mathrm{O} 2$ and $\mathrm{O} 4$ for $\mathrm{T}$, where $\mathrm{x} / \mathrm{y}$ means a bidentate coordination to two nucleobase atoms. Starting structural parameters of the hydrated metal ions have been taken from an idealized octahedral structure. Initial coordination distances of the metal ions to the nucleobase atoms and to the oxygens of water were adopted from coordination distances of the 
HF/3-21G optimized structures of the hydrated metal ions. The investigated models are schematically shown in Figure 1, all studied arrangements are displayed in the Supporting Information (Figure S1).

Optimized Structures. Geometry optimizations were carried out in two steps. First, all structures have been optimized at the HF/3-21G level. Then, the resulting structures were subjected to further optimizations using the B3LYP variant ${ }^{52-55}$ of densityfunctional theory. The $6-311 \mathrm{G}^{* *}$ basis set was employed for the $\mathrm{Mg}^{2+}$ complexes, similarly to previous studies, ${ }^{35}$ while for the $\mathrm{Mn}^{2+}$ complexes, the $\mathrm{pVDZ}^{57}$ basis set was applied. Further basis sets were also tested: the CRENBL pseudo-potential of Christiansen ${ }^{58}$ for the $\mathrm{Mn}^{2+}$ and the $\mathrm{pVTZ}^{57}$ basis set for both ions. The $\mathrm{pVDZ}$ basis was selected based on the computational cost and the marginal difference between the geometries of the optimized structures obtained with the different basis sets. The structures derived from the DFT(B3LYP)/6-311G** $\left(\mathrm{Mg}^{2+}\right.$ complexes) and DFT(B3LYP)/pVDZ( $\mathrm{Mn}^{2+}$ complexes) optimizations with the lowest MP2/pVTZ ${ }^{38}$ interaction energies were subjected to further analysis.

Interaction Energies. To test the basis set dependence of the interaction energies, a series of interaction energy calculations were carried out at the DFT(B3LYP) level using five different basis sets: $6-31 \mathrm{G}^{* *},{ }^{59-61} \mathrm{pVDZ}, \mathrm{VTZ}$, and pVTZ for the G-O6 and G-N7 inner-shell and the G N7/O6 outer-shell complex of $\mathrm{Mg}^{2+}$ and $\mathrm{Mn}^{2+}$ metal cations. The $6-311++\mathrm{G}(2 \mathrm{~d}, 2 \mathrm{p})^{51,56}$ basis set was also applied for the $\mathrm{Mg}^{2+}$ complexes. Based on the convergence of the resulting interaction energies, the MP2/pVTZ method was selected to compute the interaction energies for all optimized complexes. The interaction energies were corrected for BSSE as follows:

$$
E_{\text {int }}(\mathrm{AB})=E_{\mathrm{AB}}(\mathrm{AB})-E_{\mathrm{A}}(\mathrm{AB})-E_{\mathrm{B}}(\mathrm{AB})
$$

where $E_{\text {int }}$ is the interaction energy, $E_{\mathrm{AB}}$ is the total energy of the complex, and $E_{\mathrm{A}}(\mathrm{AB})$ and $E_{\mathrm{B}}(\mathrm{AB})$ are the monomer energies calculated in the presence of the full basis set of the dimer. We considered the hydrated metal ion (A) and the nucleobase (B) as interacting monomer units. The geometry optimizations and the interaction energy calculations were carried out with the Gaussian $03^{62}$ program package.

Gas-Phase Interaction-Energy Decomposition. Contributions of the different components to the total interaction energy were estimated by the NEDA partitioning scheme at the HF level. Since the correlation-consistent basis sets cc-pVXZ, $X=2,3$, $4^{63}$ provide a reliable partitioning of the interaction energy, the cc-pVDZ basis set was employed for the energy decomposition analysis on the $\mathrm{C}, \mathrm{O}, \mathrm{N}, \mathrm{H}$, and $\mathrm{Mg}$ atoms, whereas the ccpVTZ set ${ }^{64}$ was employed for the Mn atom. In the framework of the NEDA approach, the interaction energy is expressed as

$$
E_{\mathrm{int}}=E_{\mathrm{ES}}+E_{\mathrm{POL}}+E_{\mathrm{CT}}+E_{\mathrm{EX}}+E_{\mathrm{DEF}}
$$

where $E_{\text {int }}$ is the interaction energy, $E_{\mathrm{ES}}$ is the electrostatic, $E_{\mathrm{POL}}$ is the polarization, $E_{\mathrm{CT}}$ is the charge transfer, $E_{\mathrm{EX}}$ is the exchange, and $E_{\mathrm{DEF}}$ is the deformation energy component. NEDA calculations were performed with the NBO 5.065,66 program linked to the GAMESS ${ }^{67,68}$ package.

Solvation Energies. The effect of hydration on the interaction energies was computed according to the thermodynamic cycle presented in Figure 2,

$$
\Delta G_{\mathrm{aq}}{ }^{\text {int }}=\Delta G_{\mathrm{g}}^{\text {int }}+\Delta G_{\mathrm{MeB}}^{\text {solv }}-\left(\Delta G_{\mathrm{Me}}{ }^{\text {solv }}+\Delta G_{\mathrm{B}}{ }^{\text {solv }}\right)
$$

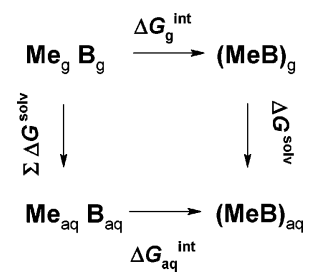

Figure 2. Thermodynamic cycle used to compute the interaction freeenergy in solution. The subscripts $g$ and aq stand for gas phase and solution, respectively.

where $\Delta G_{\mathrm{g}}$ int and $\Delta G_{\mathrm{aq}}$ int are the Gibbs interaction free-energies between the hydrated metal ions (Me) and the nucleobase (B) in the gas phase and in aqueous solution, respectively, while $\Delta G_{X}{ }^{\text {solv }}$ is the solvation free-energy of the $\mathrm{X}(\mathrm{Me}, \mathrm{B}$ or $\mathrm{MeB})$ species.

The polarizable continuum model $(\mathrm{PCM})^{69,70}$ at the DFT(B3LYP)/6-31G* level was applied to compute the solvation free-energies of the penta- and hexahydrated metal ions, the nucleobases, and the complexes. Changes in monomer structures upon complex formation were ignored and all charges were refitted for the hydration free-energy calculation. $\Delta G_{\mathrm{g}}$ int was assumed to approximate $E_{\text {int }}$ computed in the gas phase; hence, neglecting entropic effects. ${ }^{34}$ Hydration free-energies were determined using three different dielectric coefficient values: 40, 60, and 78.4. The hydration free-energies were obtained by the Gaussian 03 package. ${ }^{62}$

\section{Results and Discussion}

Structures. The nucleobase complexes were optimized with metal ions coordinated at all possible sites, as described in the Methods Section. All the resulting structures are displayed in Figure S1 of the Supporting Information. The complexes with the lowest gas-phase interaction energies exhibit identical coordination sites for the two metal ions. For the inner-shell complexes, these are $\mathrm{N} 7$ for $\mathrm{A}, \mathrm{O} 6$ for $\mathrm{G}, \mathrm{O} 2$ for $\mathrm{C}$, and $\mathrm{O} 4$ for T. For the outer-shell complexes, these are N7/N6 for A, N7/ O6 for $\mathrm{G}, \mathrm{O} 2 / \mathrm{N} 1$ for $\mathrm{C}$, and $\mathrm{O} 4$ for $\mathrm{T}$.

Analysis of the optimized structures was based on (i) the strength of the interaction between the metal and the nucleobase, and (ii) the distortions of the coordination sphere from the ideal octahedral structure. The representative structural parameters are summarized in Table 1. Despite the difference between the ionic radii of the $\mathrm{Mn}^{2+}$ and $\mathrm{Mg}^{2+}$ ions, $0.80 \AA$ vs $0.65 \AA{ }^{71}$ the length of the metal-base contacts are surprisingly similar in the inner-shell complexes of the two metal ions, with deviations less than $0.07 \AA$ between them. In outer-shell complexes the metal ion has little impact on the distance between the water molecules coordinated directly to the base and the contacting base atoms. Larger disparities can be observed in the coordination distances to the water molecules: $\mathrm{Mn}^{2+}$ binds to the coordinated water molecules more loosely than the $\mathrm{Mg}^{2+}$ ions, with coordination distances larger by $0.12 \AA$ in average. Furthermore, the lengths of the water coordination distances vary more for $\mathrm{Mn}^{2+}$, indicating a more flexible hydration sphere (see standard deviations in Table 1). In accordance with this observation, the angles of both the axial and apical ligands in the $\mathrm{Mn}^{2+}-$ nucleobase complexes deviate more from the ideal structure than the corresponding parameters of the $\mathrm{Mg}^{2+}$ complexes. Interestingly, the structures of the outer-shell complexes differ from the ideal octahedral geometry as much as the inner-shell complexes. The larger flexibility of the outershell $\mathrm{Mn}^{2+}$ complexes can lead to qualitative differences in the hydrogen-bonding patterns. For example, in the case of the N6/ N7 outer-shell complex with A, an extra hydrogen bond is 
TABLE 1: Characteristic Structural Parameters of Nucleobase Complexes with $\mathrm{Mg}^{2+}$ and $\mathrm{Mn}^{2+} \mathrm{Ions}^{a}$

\begin{tabular}{|c|c|c|c|c|c|}
\hline & & \multicolumn{2}{|c|}{ Mg } & \multicolumn{2}{|c|}{ Mn } \\
\hline & & A-N7 & G-06 & A-N7 & G-06 \\
\hline & $\mathbf{R}(\mathrm{WMe})$ & $2.108 \pm 0.025$ & $2.094 \pm 0.029$ & $2.224 \pm 0.035$ & $2.204 \pm 0.044$ \\
\hline & $\mathbf{R}(\mathrm{MeB})$ & 2.200 & 2.040 & 2.210 & 2.110 \\
\hline & $\mathbf{R}(\mathrm{MeCM})$ & 3.872 & 4.423 & 3.854 & 4.480 \\
\hline & $\zeta$ & $8.087 \pm 1.799$ & $7.477 \pm 4.728$ & $10.640 \pm 1.416$ & $10.367 \pm 5.408$ \\
\hline & $\varphi$ & $92.767 \pm 3.308$ & $93.188 \pm 4.826$ & $94.898 \pm 5.416$ & $95.001 \pm 4.368$ \\
\hline \multirow[t]{11}{*}{ inner-shell } & & $\mathrm{C}-\mathrm{O2}$ & T-04 & $\mathrm{C}-\mathrm{O2}$ & T-04 \\
\hline & $\mathbf{R}(\mathrm{WMe})$ & $2.088 \pm 0.026$ & $2.110 \pm 0.023$ & $2.192 \pm 0.029$ & $2.224 \pm 0.014$ \\
\hline & $\mathbf{R}(\mathrm{MeB})$ & 2.040 & 2.000 & 2.120 & 2.040 \\
\hline & $\mathbf{R}(\mathrm{MeCM})$ & 4.153 & 4.180 & 4.226 & 4.390 \\
\hline & $\zeta$ & $8.093 \pm 3.159$ & $5.253 \pm 3.695$ & $9.763 \pm 5.580$ & $9.610 \pm 7.051$ \\
\hline & $\varphi$ & $91.396 \pm 4.887$ & $92.781 \pm 2.376$ & $92.548 \pm 6.180$ & $96.473 \pm 3.429$ \\
\hline & & A-N7/N6 & G-N7/O6 & A-N7N6 & G-N7/O6 \\
\hline & $\mathbf{R}(\mathrm{WMe})$ & $2.091 \pm 0.015$ & $2.085 \pm 0.014$ & $2.198 \pm 0.028$ & $2.180 \pm 0.021$ \\
\hline & $\mathbf{R}(\mathrm{WB})$ & 2.827 & 2.703 & 2.78 & 2.703 \\
\hline & $\mathbf{R}(\mathrm{MeCM})$ & 5.198 & 5.585 & 5.208 & 5.643 \\
\hline & $\zeta$ & $6.657 \pm 3.005$ & $6.165 \pm 1.705$ & $7.733 \pm 3.488$ & $8.490 \pm 2.570$ \\
\hline \multirow[t]{5}{*}{ outer-shell } & & C-O2/N3 & T-04 & $\mathrm{C}-\mathrm{O} 2 / \mathrm{N} 3$ & T-O4 \\
\hline & $\mathbf{R}(\mathrm{WMe})$ & $2.085 \pm 0.014$ & $2.088 \pm 0.007$ & $2.193 \pm 0.011$ & $2.192 \pm 0.004$ \\
\hline & $\mathbf{R}(\mathrm{WB})$ & 2.717 & 2.75 & 2.947 & 2.726 \\
\hline & $\mathbf{R}(\mathrm{MeCM})$ & 5.113 & 5.843 & 5.747 & 6.076 \\
\hline & $\zeta$ & $5.887 \pm 0.562$ & $5.990 \pm 0.144$ & $8.850 \pm 0.511$ & $7.550 \pm 0.254$ \\
\hline
\end{tabular}

${ }^{a} R$ is the distance (in $\AA$ ) between the coordinated nucleobase atoms (B), the metal ions (Me), and the oxygen atoms of water (W), whereas CM designates the center of mass of the nucleobase. $\zeta$ and $\varphi$ characterize the angular deviations (in degrees) from the ideal octahedral geometry, where $\zeta$ is the deviation of the apical atoms from linearity and $\varphi$ is computed for the equatorial atoms (see Figure 1 for numbering of the atoms).

TABLE 2: Gas-Phase Interaction Energies of Nucleobases with Hydrated $\mathrm{Mg}^{2+}$ and $\mathrm{Mn}^{2+}$ Ions Obtained at the MP2 Level Using the 6-311 + G(2d,2p) and pVTZ Basis Sets, Respectively, with BSSE Corrections Included ${ }^{a}$

\begin{tabular}{cllc}
\hline \multirow{5}{*}{ inner-shell } & & Mg & Mn \\
\hline & A-N7 & -61.02 & -56.89 \\
& C-O2 & -85.76 & -79.93 \\
& G-O6 & -88.08 & -83.01 \\
& T-O4 & -56.04 & -51.05 \\
\multirow{5}{*}{ outer-shell } & A-N7/N6 & -48.95 & -48.33 \\
& C-O2 & -71.2 & -74.29 \\
& G-N7/O6 & -74.04 & -72.63 \\
& T-O4 & -50.15 & -51.15
\end{tabular}

${ }^{a}$ The atom numbering refers to the contact sites. All energy values are given in $\mathrm{kcal} \mathrm{mol}^{-1}$.

formed between one of the water molecules and N6 of A. Another example is the $\mathrm{O} 2 / \mathrm{N} 3$ cytosine outer-shell complex, in which a bond with $\mathrm{N} 3$ breaks and a new one with $\mathrm{O} 2$ forms in the $\mathrm{Mn}^{2+}$ complex. Such rearrangements in the hydrogenbonding network cannot take place in the corresponding $\mathrm{Mg}^{2+}$ complexes due to the rigidity of the coordination sphere.

Interaction Energies. The gas-phase BSSE-corrected interaction energies $\left(E_{\text {int }}\right)$ of the penta- and hexahydrated metal ions with nucleobases, computed at the MP2/pVTZ level, are summarized in Table 2 for the complexes with lowest interaction energies, whereas results for all models are displayed in the Supporting Information (Table S1).

All inner-shell complexes favor $\mathrm{Mg}^{2+}$ over $\mathrm{Mn}^{2+}$, as reflected by the larger negative $E_{\text {int }}$ values. Discrepancies between the $\mathrm{Mg}^{2+}$ and $\mathrm{Mn}^{2+}$ interaction energies increase in the outer-shell complexes: purine bases ( $\mathrm{G}$ and $\mathrm{A}$ ) favor $\mathrm{Mg}^{2+}$, while pyrimidines ( $\mathrm{T}$ and $\mathrm{C}$ ) prefer $\mathrm{Mn}^{2+}$. The affinities of nucleobases for the metal ions correlate neither with nucleobase-metal ion separation nor with the magnitude of distortion from the ideal octahedral structure. The differences between the $E_{\text {int }}$ values of the four nucleobases are dependent on the metal ion type, especially for outer-shell complexes, where they are smaller for the $\mathrm{Mn}^{2+}$ complexes (see discussion below).

Surprisingly, $E_{\text {int }}$ values are significantly more favorable for $\mathrm{G}$ and $\mathrm{C}$ than for $\mathrm{A}$ and $\mathrm{T}$ with either metal ions. The gap between the interaction energies of $\mathrm{G}$ versus $\mathrm{A}$ and $\mathrm{C}$ versus $\mathrm{T}$ is in the range of $26-30 \mathrm{kcal} \mathrm{mol}^{-1}$ for the inner-shell complexes of both the $\mathrm{Mg}^{2+}$ and $\mathrm{Mn}^{2+}$ ions. The structural parameters do not provide apparent explanation for this as the metal-ion-nucleobase coordination distances do not show considerable deviations. For outer-shell complexes, the contact distances between the water and the coordinated nucleobase atoms exhibit a weak correlation with the variation of the $E_{\text {int }}$ values. The difference between the $G$ versus $A$ and $C$ versus $T$ interaction energies decreases in the outer-shell complexes as compared to the inner-shell ones. This decrease is due to the screening effect of the sixth water molecule, suggesting that the origin of the effect is electrostatic. The discrepancies between the $E_{\text {int }}$ values of the nucleobases are smaller in the $\mathrm{Mn}^{2+}$ complexes than in the $\mathrm{Mg}^{2+}$ ones, which might implicate a larger charge transfer in these systems.

Energy Partitioning. To reveal the origin of the differences between the interaction energies of the $\mathrm{Mg}^{2+}$ and $\mathrm{Mn}^{2+}$ complexes as well as deviations between the $E_{\text {int }}$ values of $\mathrm{G}$ versus $\mathrm{A}$ and $\mathrm{C}$ versus $\mathrm{T}$ complexes with either metal ions, we decomposed the interaction energy according to the NEDA partition scheme with results presented in Table 3. For the $\mathrm{Mg}^{2+}$ complexes, the interaction energies obtained by NEDA at the HF/cc-pVDZ level approximated the values computed at the MP2/pVTZ level within $\pm 5 \mathrm{kcal} \mathrm{mol}^{-1}$. The electric term, including the electrostatic, polarization, and self-response components, differs in a larger extent for the $\mathrm{G}$ versus $\mathrm{A}$ and $\mathrm{C}$ versus $\mathrm{T}$ bases than the core term, comprising the exchange, deformation, and electronic self-energy components. Out of the three electric components, the electrostatic term deviates most significantly, by $25.6 \mathrm{kcal} \mathrm{mol}^{-1}$ for $\mathrm{A}$ and $\mathrm{G}$ and by $36.3 \mathrm{kcal}$ $\mathrm{mol}^{-1}$ for T and C. It reveals that the difference in the $E_{\text {int }}$ values of the different nucleobases is mostly due to electrostatic 
TABLE 3: Energy Contributions to the Gas-Phase Interaction Energy $\left(E_{\text {int }}\right)$ According to the Natural Energy Decomposition Analysis (NEDA): Charge Transfer (CT), Electrostatic (ES), Polarization (POL), Exchange (EX), Deformation (DEF), and Electrical Self-Energy (SE) Terms ${ }^{a}$

\begin{tabular}{|c|c|c|c|c|c|c|c|c|c|c|c|}
\hline & & & CT & ES & POL & EX & DEF & SE & $\begin{array}{c}\text { electrical } \\
\mathbf{E S}+\mathbf{P O L}+\mathbf{S E}\end{array}$ & $\begin{array}{c}\text { core } \\
\text { EX+DEF-SE }\end{array}$ & $E_{\text {int }}$ \\
\hline \multirow{8}{*}{$\mathrm{Mg}$} & \multirow{4}{*}{ inner } & A-N7 & $-67,78$ & $-68,29$ & $-62,31$ & $-10,37$ & 151,14 & 32,32 & $-98,28$ & 108,45 & $-57,6$ \\
\hline & & $\mathrm{C}-\mathrm{O} 2$ & $-64,88$ & $-94,97$ & $-68,66$ & $-9,35$ & 148,24 & 35,67 & $-127,96$ & 103,22 & $-89,62$ \\
\hline & & G-O6 & $-77,52$ & $-93,93$ & $-75,96$ & $-9,44$ & 165,13 & 39,48 & $-130,41$ & 116,21 & $-91,72$ \\
\hline & & T-O4 & $-45,43$ & $-58,7$ & $-69,57$ & $-7,34$ & 120,69 & 36,18 & $-92,09$ & 77,17 & $-60,36$ \\
\hline & \multirow{4}{*}{ outer } & A-N7/N6 & $-68,32$ & $-53,34$ & $-35,93$ & $-7,08$ & 121,64 & 18,81 & $-70,46$ & 95,75 & $-43,03$ \\
\hline & & $\mathrm{C}-\mathrm{O} 2$ & $-69,12$ & $-80,27$ & $-45,89$ & $-7,55$ & 132,18 & 24,23 & $-101,93$ & 100,4 & $-70,65$ \\
\hline & & G-N7/O6 & $-75,88$ & $-81,17$ & $-51,06$ & $-7,64$ & 142,46 & 26,94 & $-105,29$ & 107,88 & $-73,29$ \\
\hline & & $\mathrm{T}-\mathrm{O} 4$ & $-43,62$ & $-49,88$ & $-49,31$ & $-5,69$ & 99,27 & 26,18 & $-73,01$ & 67,4 & $-49,23$ \\
\hline \multirow{4}{*}{ Mn } & inner & A-N7 & $-104,67$ & $-77,68$ & $-156,67$ & $-28,63$ & 315,32 & 80,04 & $-154,31$ & 206,65 & $-52,33$ \\
\hline & & $\mathrm{T}-\mathrm{O} 4$ & $-75,11$ & $-59,88$ & $-155,00$ & $-21,40$ & 257,9 & 79,53 & $-135,35$ & 156,97 & $-53,49$ \\
\hline & outer & A-N7/O6 & $-83,20$ & $-57,07$ & $-41,53$ & $-8,88$ & 148,94 & 21,82 & $-76,78$ & 118,24 & $-41,74$ \\
\hline & & $\mathrm{T}-\mathrm{O} 4$ & $-63,17$ & $-49,51$ & $-48,40$ & $-6,49$ & 99,27 & 26,18 & $-71,73$ & 66,60 & -43.35 \\
\hline
\end{tabular}

${ }^{a}$ The partitioning has been carried out at the Hartree-Fock level employing the cc-pVDZ basis set for C, O, N, $\mathrm{H}$, and $\mathrm{Mg}^{2+}$, and the cc-pVTZ basis set for $\mathrm{Mn}^{2+}$. All energy values are given in $\mathrm{kcal} \mathrm{mol}^{-1}$.

effects. The charge-transfer term also provides important, 19.5 $\mathrm{kcal} \mathrm{mol}^{-1}$ contribution to the interaction energy difference between $\mathrm{T}$ and $\mathrm{C}$. The effect of polarization is controversial. Polarization is more favorable for the $\mathrm{G}$ than the A complex, but for $\mathrm{C}$ versus $\mathrm{T}$ it differs to a smaller extent in the opposite direction (more negative for the $\mathrm{T}$ complex). The differences in the deformation terms indicate that wave functions of $\mathrm{G}$ and $\mathrm{C}$ undergo larger distortions upon association with hydrated $\mathrm{Mg}^{2+}$ than those of $\mathrm{A}$ and $\mathrm{T}$.

For $\mathrm{Mn}^{2+}$, the partitioning of the interaction energies could only be performed for the A and T complexes. For the $\mathrm{G}$ and C complexes a formal shift of one electron occurred from the base to the metal ion, leading to a strong deviation between the sum of the contributions and the total $E_{\text {int }}$ value obtained at the HF/cc-pVDZ level. This formal one-electron shift is probably due to a problem in the NBO search algorithm (personal communication with E.D. Glendening).

The differences between the electric and core components of the interaction energy for the corresponding $\mathrm{A}$ and $\mathrm{T}$ complexes with $\mathrm{Mn}^{2+}$ and $\mathrm{Mg}^{2+}$ appear to be significant: the electric terms are more favorable for the inner-shell $\mathrm{Mn}^{2+}$ complexes, while the core terms change in the opposite direction. Out of the three electric components, the largest deviation is seen for the polarization term of the $\mathrm{A}-\mathrm{Mn}^{2+}$ and $\mathrm{T}-\mathrm{Mn}^{2+}$ complexes that exceeds the corresponding values of the $\mathrm{Mg}^{2+}$ complexes by 94 and $85 \mathrm{kcal} \mathrm{mol}^{-1}$, respectively. $\mathrm{Mn}^{2+}$ with open $\mathrm{d}$ orbitals is more polarizable than $\mathrm{Mg}^{2+}$ without them, and this allows a smaller charge separation between the metal ion and the nucleobase. Consequently, the charge-transfer term was also found to be larger for the $\mathrm{Mn}^{2+}$ than for the $\mathrm{Mg}^{2+}$ complexes. Increase of the polarization and charge-transfer components is accompanied by significantly larger deformation energies (by $98 \mathrm{kcal} \mathrm{mol}^{-1}$ for $\mathrm{A}$ and $80 \mathrm{kcal} \mathrm{mol}^{-1}$ for T) indicating a more severe wave function distortion of the $\mathrm{Mn}^{2+}$ as compared to the $\mathrm{Mg}^{2+}$ complexes. In the outer-shell complexes, the insertion of the sixth water ligand remarkably suppresses the polarization term, resulting in better agreement between the $E_{\text {int }}$ values of $\mathrm{Mg}^{2+}$ and $\mathrm{Mn}^{2+}$ complexes. Although the charge-transfer terms also decrease in the outer-shell $\mathrm{Mn}^{2+}$ complexes as compared to the inner-shell ones, they still considerably exceed the corresponding $\mathrm{Mg}^{2+}$ values. Hence, in spite of the $50 \%$ reduction of the distortion terms as compared to the inner-shell complexes, they are still significantly larger in the $\mathrm{Mn}^{2+}$ than in the $\mathrm{Mg}^{2+}$ outer-shell complexes.
TABLE 4: Solvation Gibbs Free Energies Obtained by the PCM Method for the Complex (C), the Hydrated Metal Ion (Me), and the Base (B) Using a Dielectric Constant of $40^{a}$

\begin{tabular}{|c|c|c|c|c|c|c|c|}
\hline & & $\epsilon=40.0$ & $\Delta G_{\text {solv }}(\mathrm{C})$ & $\Delta G_{\text {solv }}(\mathrm{B})$ & $\Delta G_{\text {solv }}(\mathrm{M})$ & $\Delta G^{\mathrm{corr}}$ & $\Delta \boldsymbol{G}_{\text {int }}$ \\
\hline \multirow{8}{*}{$\begin{array}{l}\text { inner- } \\
\text { shell }\end{array}$} & \multirow{4}{*}{$\mathrm{M}$} & A-N7 & & -1399 & -21112 & 52.11 & -8.91 \\
\hline & & $\mathrm{C}-\mathrm{C}$ & & & & & \\
\hline & & G-O6 & & & & & \\
\hline & & $\mathrm{T}-\mathrm{O} 4$ & -171.48 & - & - & 52.45 & -3.5 \\
\hline & \multirow{4}{*}{$\mathrm{Mn}$} & A-I & -1 & -1 & -2 & 47.14 & -9 . \\
\hline & & C- & & & & & \\
\hline & & G-O6 & & & & & -11.82 \\
\hline & & $\mathrm{T}-\mathrm{O} 4$ & & & & 48 & -2.14 \\
\hline \multirow{8}{*}{$\begin{array}{l}\text { outer- } \\
\text { shell }\end{array}$} & \multirow{4}{*}{$\mathrm{Mg}$} & & & & & & -1 \\
\hline & & $\mathrm{C}-\mathrm{O} 2$ & & & & & \\
\hline & & G-N7/ & & & & & - \\
\hline & & T-O4 & -164.63 & -12.93 & -192.28 & 40.58 & -9.57 \\
\hline & \multirow{4}{*}{$\mathrm{Mn}$} & A-N7 & -165.34 & -1 & -1 & 36.31 & -12 \\
\hline & & & & $-5+2>$ & & 56.78 & 17.51 \\
\hline & & G-N7/O6 & & -24 & -1 & 58.03 & -14.60 \\
\hline & & $\mathrm{T}-\mathrm{O} 4$ & -163.03 & -12.85 & -190.76 & 40.58 & -10.57 \\
\hline
\end{tabular}

${ }^{a} \Delta G^{\text {corr }}$ is the sum of the solvation energies according to the thermodynamic cycle of Figure 2, $\Delta G_{\text {int }}$ is the interaction Gibbs free energy in solution. All values are given in $\mathrm{kcal} \mathrm{mol}^{-1}$.

Hydration Energies. Comparison of the gas-phase interaction energies of the corresponding inner and outer-shell complexes of the four nucleobases with $\mathrm{Mg}^{2+}$ and $\mathrm{Mn}^{2+}$ ions points to the importance of hydration in modulating metal ion selectivity. To assess the effect of solvation on the affinity of the two metal ions toward the nucleobases, we determined the solvation freeenergies of all complexes and computed the interaction energies in solution according to eq 3 in the Solvation Energies section. Since dielectric properties of the solvent medium can determine the binding mode of magnesium in biological systems, ${ }^{72}$ different dielectric coefficient values were used for computing hydration free-energies. The dielectric constant at the surface of DNA was estimated to be in the range of $30-50,{ }^{36,73}$ thus calculations were performed using values of 40, 60, and also using $\epsilon=78.4$ of bulk water. The results with $\epsilon=40$ are summarized in Table 4, values obtained using dielectric constants of 60 and 78.4 are presented in Table S2 and Table $\mathrm{S} 3$ of the Supporting Information. Hydration free-energies and the correction to the gas-phase interaction energy $\left(\Delta G^{\text {corr }}\right)$, obtained as a sum of solvation and desolvation terms $\left(\Delta G_{\text {solv }}{ }^{\text {compl }}\right.$ $-\Delta G_{\text {solv }}{ }^{\mathrm{Me}}-\Delta G_{\text {solv }}{ }^{\mathrm{B}}$ ) using $\epsilon=40$ (Table 4) and 60 (Table S1) are very similar to each other. Results computed with a dielectric constant of 78.4 are also consistent with these values 
TABLE 5: Base-Substitution Energies in the Gas-Phase Expressed as $\Delta E_{\text {int }}=E_{\text {int }}($ row $)-E_{\text {int }}($ col $)$ for the $\mathrm{Mg}^{2+}$ Complexes (Lower Triangle) and $\Delta E_{\text {int }}=E_{\text {int }}(\mathrm{col})-$ $E_{\text {int }}($ row $)$ for the $\mathrm{Mn}^{2+}$ Complexes (Upper Triangle), where $E_{\text {int }}(\mathrm{col})$ and $E_{\text {int }}($ row $)$ are the Interaction Energies of the Hydrated Metal Ion with Nucleobases Displayed in Rows and Columns, Respectively ${ }^{a}$

\begin{tabular}{crrcr}
\hline I & G & A & C & \multicolumn{1}{c}{ T } \\
\hline $\mathbf{G}$ & & 26.1 & 3.1 & 32.0 \\
$\mathbf{A}$ & 27.1 & & -23.0 & 5.8 \\
$\mathbf{C}$ & 2.3 & -24.7 & & 28.9 \\
$\mathbf{T}$ & 32.0 & 5.0 & 29.7 & \\
II & $\mathbf{G}$ & $\mathbf{A}$ & $\mathbf{C}$ & \multicolumn{1}{c}{$\mathbf{T}$} \\
\hline $\mathbf{G}$ & & 24.3 & -1.7 & 21.5 \\
$\mathbf{A}$ & 25.1 & & -26.0 & -2.8 \\
$\mathbf{C}$ & 2.8 & -22.3 & & 23.1 \\
$\mathbf{T}$ & 23.9 & -1.2 & 21.2 &
\end{tabular}

${ }^{a}$ I: inner-shell complexes. II: outer-shell complexes. All values are given in $\mathrm{kcal} \mathrm{mol}^{-1}$.

with the exception of the hydration free-energies of $\mathrm{Mn}^{2+}$ outershell complexes. In this case, the order of the interaction freeenergies do not follow the gas-phase trend so that $\Delta G^{\text {int }}$ of $\mathrm{C}$ is less favorable then that of $\mathrm{T}$. The observations presented below express the general behavior of metal ion complexes in the three dielectric media, any deviations will be mentioned explicitly.

The correction to the gas-phase interaction energy ( $\left.\Delta G^{\text {corr }}\right)$ derived from the hydration free-energies of the complex and the hydrated metal ion and base moieties inversely correlates with the $E_{\text {int }}$ values in the gas phase: it is the least positive for A and largest for G. Similarly to their values in the gas phase, interaction free-energies of the $\mathrm{G}$ and $\mathrm{C}$ complexes of both metal ions in solution are more negative than those of $\mathrm{A}$ and $\mathrm{T}$ in both binding modes (with the exception of $\mathrm{T}$ and $\mathrm{C}$ in the outershell complex of $\mathrm{Mn}^{2+}$, as mentioned above). Due to the decreased desolvation energy of the nucleobase, the $\mathrm{C}-\mathrm{Mg}^{2+}$ and the $\mathrm{C}-\mathrm{Mn}^{2+}$ complexes have the largest (negative) interaction energies in solution, in contrast to the $\mathrm{G}-\mathrm{Mg}^{2+}$ and $\mathrm{G}-\mathrm{Mn}^{2+}$ complexes in the gas phase. As expected, solvation free-energies of the $\mathrm{Mn}^{2+}$ complexes are smaller (less negative) than those of the $\mathrm{Mg}^{2+}$ complexes, likely due to the result of larger polarization and charge-transfer effects. The differences in complex hydration free-energies become smaller with the decreasing dielectric constant. The solvation energies of the hydrated $\mathrm{Mn}^{2+}$ ions are also smaller than those of $\mathrm{Mg}^{2+}$, which also derives from differences in the polarization and chargetransfer terms. As expected, the deviation between the solvation free-energies of the hexahydrated $\mathrm{Mg}^{2+}$ and $\mathrm{Mn}^{2+}$ ions decreases as compared to the penta-hydrated forms. Similarly to the gas phase, the interaction energies of the $\mathrm{Mg}^{2+}$ inner-shell complexes are larger (more negative) than those of $\mathrm{Mn}^{2+}$, whereas $\mathrm{Mn}^{2+}$ is preferred in outer-shell complexes in solution. As compared to the gas phase, the deviations between the interaction energies of the four nucleobase complexes decrease substantially in solution, due to screening of the electrostatic interactions in the bulk phase.

Base-Substitution Energies. To elucidate the origin of the alternate selectivity of the metal ions, we computed the basesubstitution energies as the difference of the appropriate gasphase interaction energies (Table 5). The $\Delta E_{\text {int }}$ values indicate significant variations in the preference of the two metal ions for the different nucleobases. The $\mathrm{G} \rightarrow \mathrm{A}, \mathrm{G} \rightarrow \mathrm{T}, \mathrm{A} \rightarrow \mathrm{C}$, and $\mathrm{C} \rightarrow \mathrm{T}$ substitutions are accompanied by a large change in the interaction energy, whereas the $\mathrm{G} \rightarrow \mathrm{C}$ and $\mathrm{A} \rightarrow \mathrm{T}$ replacements are energetically less demanding in both the inner and outershell complexes of either metal ion. This can be explained by
TABLE 6: Base-Substitution Free Energies in Solution Obtained by the PCM Model, Computed as $\Delta E_{\text {int }}=$ $E_{\text {int }}($ row $)-E_{\text {int }}\left(\right.$ col) for the $\mathbf{M g}^{2+}$ Complexes (Lower Triangle) and $\Delta E_{\text {int }}=E_{\text {int }}($ col $)-E_{\text {int }}($ row $)$ for the $\mathbf{M n}^{2+}$ Complexes (Upper Triangle), where $E_{\text {int }}(\mathrm{col})$ and $E_{\text {int }}($ row $)$ are the Interaction Energies of the Hydrated Metal Ion with Nucleobases Displayed in Rows and Columns, Respectively ${ }^{a}$

\begin{tabular}{crrrr}
\hline I & G & A & C & T \\
\hline G & & 2,1 & $-1,5$ & 9,7 \\
$\mathbf{A}$ & 3,3 & & $-3,5$ & 7,6 \\
$\mathbf{C}$ & $-1,9$ & $-5,3$ & & 11,2 \\
$\mathbf{T}$ & 8,6 & 5,3 & 10,6 & \\
II & $\mathbf{G}$ & $\mathbf{A}$ & $\mathbf{C}$ & $\mathbf{T}$ \\
\hline $\mathbf{G}$ & & 2,6 & $-2,9$ & 4,0 \\
$\mathbf{A}$ & 2,8 & & $-5,5$ & 1,5 \\
$\mathbf{C}$ & $-0,8$ & $-3,6$ & & 6,9 \\
$\mathbf{T}$ & 5,0 & 2,2 & 5,8 &
\end{tabular}

${ }^{a}$ I: inner-shell complexes. II: outer-shell complexes. All values are given in $\mathrm{kcal} \mathrm{mol}^{-1}$.

the large gap between the interaction energies of $\mathrm{G}$ versus $\mathrm{A}$ and $\mathrm{C}$ versus $\mathrm{T}$ that was discussed above. Interestingly, differences between the base substitution energies of the $\mathrm{Mg}^{2+}$ and $\mathrm{Mn}^{2+}$ complexes in the gas phase are relatively small, especially for the inner-shell complexes, the largest $\Delta \Delta E_{\mathrm{int}} \mathrm{Mg} \rightarrow \mathrm{Mn}$ $=1.7 \mathrm{kcal} \mathrm{mol}^{-1}$ difference is obtained for the $\mathrm{A} \rightarrow \mathrm{C}$ replacement. In outer-shell complexes, base-substitution energies of the $\mathrm{Mg}^{2+}$ and $\mathrm{Mn}^{2+}$ complexes differ more than in the innershell case. The largest deviations are seen for the $\mathrm{G} \rightarrow \mathrm{C}$ and $\mathrm{A} \rightarrow \mathrm{C}$ replacements, where $\Delta \Delta E_{\mathrm{int}} \mathrm{Mg} \rightarrow \mathrm{Mn}$ is -4.5 and -3.7 $\mathrm{kcal} \mathrm{mol}^{-1}$, respectively. The differences between the basesubstitution energies of the two metal ions are also considerable for the $\mathrm{G} \rightarrow \mathrm{T}$ and $\mathrm{C} \rightarrow \mathrm{T}$ replacements, 2.4 and $1.9 \mathrm{kcal} \mathrm{mol}^{-1}$, respectively. Inclusion of the sixth water ligand affects the polarization and charge-transfer terms in a larger extent for $\mathrm{Mn}^{2+}$ than for $\mathrm{Mg}^{2+}$, especially in the outer-shell complexes. Based on these results we hypothesized that incorporating the effect of bulk hydration into the interaction energies will result in lower, more realistic base substitution free-energies with greater difference between the two metal ions. Base substitution freeenergies computed with $\Delta G_{\text {int }}$ values presented in Table 4 using a dielectric constant of 40 are summarized in Table 6. Base substitution free-energies obtained using $\epsilon=60$ and $\epsilon=78.4$ are presented in Table S4 and Table S5 of the Supporting Information.

As expected, the magnitude of the base substitution freeenergies in solution lowered considerably as compared to the gas-phase values. This, however, does not increase the difference between the base substitution free-energies computed for the inner-shell complexes of the two metal ions. Similarly to the gas phase, base substitution free-energies vary for the two metal ions between 0.4 and $2.3 \mathrm{kcal} \mathrm{mol}^{-1}$. For outer-shell complexes, the base substitution energies heavily depend on the dielectric properties of the medium. While with a high dielectric constant $(\epsilon=78.4)$ base substitution free-energies computed for $\mathrm{Mg}^{2+}$ and $\mathrm{Mn}^{2+}$ complexes deviate significantly in solution, even up to $8 \mathrm{kcal} \mathrm{mol}^{-1}$ (for replacements of $\mathrm{T}$ ), in lower dielectrics (Table 6 and Table S5), differences between $\mathrm{Mg}^{2+}$ and $\mathrm{Mn}^{2+}$ complexes do not exceed $2.3 \mathrm{kcal} \mathrm{mol}^{-1}$. In general, we observe that base-substitutions to $\mathrm{A}, \mathrm{G}$, and $\mathrm{C}$ are more facilitated in $\mathrm{Mn}^{2+}$ complexes as compared to $\mathrm{Mg}^{2+}$ complexes and in outershell complexes in all cases except of $\mathrm{C} \rightarrow \mathrm{T}$. We must note, however, that base substitutions are not symmetric in the two directions. 


\section{Conclusions}

Interaction energies of $\mathrm{Mg}^{2+}$ and $\mathrm{Mn}^{2+}$ complexes with the four nucleobases inevitably show that these metal ions exhibit preference for the same binding sites (atoms). Optimized structures of the corresponding complexes are, nevertheless, markedly different. Hydrated $\mathrm{Mn}^{2+}$-nucleobase structures deviate more from the ideal octahedral arrangement and are more flexible than hydrated $\mathrm{Mg}^{2+}$ complexes. The tolerance for larger distortions in the $\mathrm{Mn}^{2+}$ complexes can result in different hydrogen-bonding patterns, formation of new contacts between the ligated water molecules and the nucleobase atoms can be induced, e.g., for cytosine. The larger variations in the coordination geometry might also imply greater flexibility of the $\mathrm{Mn}^{2+}$ complexes as it has been reflected by $\mathrm{Mn}^{2+}$ containing proteinDNA crystal structures. ${ }^{74}$

It appears that all inner-shell complexes including a direct contact between the metal ions and the nucleobase favor $\mathrm{Mg}^{2+}$ over $\mathrm{Mn}^{2+}$. In outer-shell complexes, however, the screening of the electrostatic interactions by the sixth water ligand brings the interaction energies of the two metal ions into closer agreement that indicates the preference of the purine bases for $\mathrm{Mn}^{2+}$ ions instead of $\mathrm{Mg}^{2+}$. Interestingly, in both the innerand outer-shell complexes, a large discrepancy was observed between the interaction energies of $G$ versus $A$ and $C$ versus $T$, indicating a weaker complex between the latter bases and either metal ion. To unveil the reason, the interaction energies were partitioned to electronic, charge transfer, and core repulsion terms using the NEDA partition scheme. For $G$ and $C$ the electric term has a larger negative value than for $\mathrm{A}$ and $\mathrm{T}$. The most significant deviation is observed in the electrostatic component that is accompanied by a marked distortion of the wave function upon complex formation. The dominance of the so-called nonelectrostatic terms, the polarization and chargetransfer terms, are not beneficial for complex formation as it was demonstrated for the $\mathrm{A}$ and $\mathrm{T}$ inner-shell $\mathrm{Mn}^{2+}$ complexes as compared to the corresponding $\mathrm{Mg}^{2+}$ systems. This reveals an important difference between the two metal ions: the more polarizable $\mathrm{Mn}^{2+}$ ions allow a larger charge flow to the metal ion (increasing the covalent character of the complex) that is disadvantageous for binding to the nucleobase. Indeed, for outershell complexes, where the discrepancy between the electrostatic terms computed for the two metal ions are smaller, the interaction energies are in closer agreement with each other.

Inclusion of the solvation free-energies demonstrate that bulk solvation modulates the balance between electrostatic and nonelectrostatic terms and thereby alters the preference of the two metal ions toward different nucleobases. In this sense, the DNA sequence context as well as the protein side-chains can modulate the metal ion binding affinities via simple solvation effects. Solvation was observed to decrease sequence discrimination for both metal ions but in a larger extent for $\mathrm{Mn}^{2+}$.

Overall, we can conclude that the reduced selectivity of $\mathrm{Mn}^{2+}$ toward the nucleobases is due to two main factors: larger tolerance for distortions and larger polarizability that is coupled to less favorable solvation of the complexes. Thus the ab inito calculations provide useful insights into the molecular background of the discrepant binding properties of $\mathrm{Mg}^{2+}$ and $\mathrm{Mn}^{2+}$ ions at the nucleobase level and could outline those factors that can also affect selectivity of the two metal ions in more complex systems.

Acknowledgment. This work was funded by grants T049073 (I.S.) T047185 (A.C.), and F046164 (M.F.) from the Hungarian Scienctific Research Fund (OTKA) as well as by the Economic
Competitiveness Operative Programme GVOP-3.2.1.-2004-040195/3.0. The support of the MRTN-CT-2005-019566 of the European FP6 and a Bolyai János fellowship for M.F. are also gratefully acknowledged.

Supporting Information Available: The Supporting Information contains Figure S1 and Table S1 showing all optimized (DFT(B3LYP)/6-311G** and DFT(B3LYP)/pVDZ) complex structures with their respective MP2 interaction energies. Tables $\mathrm{S} 2$ and $\mathrm{S} 3$ contain hydration free-energies of the complexes and the hydrated metal and base moieties using a dielectric constant of 60 and 78.4, respectively. Tables S4 and S5 summarize the base substitution free-energies obtained by using correction terms displayed in Tables S2 and S3 obtained using a dielectric constant of 60 and 78.4, respectively. This material is available free of charge via the Internet at http://pubs.acs.org.

\section{References and Notes}

(1) Serganov, A.; Polonskaia, A.; Phan, A. T.; Breaker, R. R.; Patel, D. J. Nature 2006, 441, 1167.

(2) Choi, C. J.; Kanthasamy, A.; Anantharam, V.; Kanthasamy, A. G. Neurotoxicology 2006, 27, 777 .

(3) Duan, J.; Nilsson, L. Biochemistry 2006, 45, 7483.

(4) Binolfi, A.; Rasia, R. M.; Bertoncini, C. W.; Ceolin, M.; Zweckstetter, M.; Griesinger, C.; Jovin, T. M.; Fernandez, C. O. J. Am. Chem. Soc. 2006, 128, 9893

(5) Minagawa, A.; Takaku, H.; Ishii, R.; Takagi, M.; Yokoyama, S.; Nashimoto, M. Nucleic Acids Res. 2006, 34, 3811.

(6) Ye, Q. Z.; Xie, S. X.; Ma, Z. Q.; Huang, M.; Hanzlik, R. P. Proc. Natl. Acad. Sci. U.S.A. 2006, 103, 9470.

(7) Cowan, J. A. Biometals 2002, 15, 225.

(8) Sreedhara, A.; Cowan, J. A. Biometals 2002, 15, 211

(9) Yang, W.; Lee, J. Y.; Nowotny, M. Mol. Cell 2006, 22, 5.

(10) Sträter, N.; Lipscomb, W. N.; Klabunde, T.; Krebs, B. Angew. Chem., Int. Ed. Eng. 1996, 35, 2024.

(11) Herschlag, D.; Jencks, W. P. J. Am. Chem. Soc. 1989, 111, 7587.

(12) Woodson, S. A. Curr. Opin. Chem. Biol. 2005, 9, 104.

(13) Hud, N. V.; Polak, M. Curr. Opin. Struct. Biol. 2001, 11, 293.

(14) Cowan, J. A.; Huang, H. W.; Hsu, L. Y. J. Inorg. Biochem. 1993, 52,121

(15) Subirana, J. A.; Soler-Lopez, M. Annu. Rev. Biophys. Biomol. Struct. 2003, 32, 27.

(16) Minasov, G.; Tereshko, V.; Egli, M. J. Mol. Biol. 1999, 291, 83.

(17) Chiu, T. K.; Dickerson, R. E. J. Mol. Biol. 2000, 301, 915.

(18) Huang, H. W.; Li, D.; Cowan, J. A. Biochimie 1995, 77, 729.

(19) Roberts, R. J.; Halford, S. E. Type II restriction endonucleases. In Nucleases; Linn, S. M., Lloyd, R. S., Roberts, R. J., Eds.; Cold Spring Harbor Laboratory Press: Cold Spring Harbor, NY 1993; pp 35.

(20) Taylor, J. D.; Halford, S. Biochemistry 1989, 28, 6198.

(21) Engler, L. E.; Sapienza, P.; Dorner, L. F.; Kucera, R.; Schildkraut, I.; Jen-Jacobson, L. J. Mol. Biol. 2001, 307, 619.

(22) Conlan, L. H.; Dupureur, C. M. Biochemistry 2002, 41, 1335.

(23) Bowen, L. M.; Dupureur, C. M. Biochemistry 2003, 42, 12643.

(24) Vermote, C. L.; Halford, S. E. Biochemistry 1992, 31, 6082.

(25) Hsu, M.; Berg, P. Biochemistry 1978, 17, 131.

(26) Xu, S. Y.; Schildkraut, I. J. Bacteriol. 1991, 173, 5030.

(27) Thielking, V.; Selent, U.; Kohler, E.; Landgraf, A.; Wolfes, H.; Alves, J.; Pingoud, A. Biochemistry 1992, 31, 3727.

(28) Pingoud, A.; Fuxreiter, M.; Pingoud, V.; Wende, W. Cell. Mol. Life Sci. 2005, 62, 685 .

(29) Dupureur, C. M.; Dominguez, M. A., Jr. Biochemistry 2001, 40, 387.

(30) Etzkorn, C.; Horton, N. C. J. Mol. Biol. 2004, 343, 833.

(31) Horton, N. C.; Perona, J. J. Biochemistry 2004, 43, 6841.

(32) Kielkopf, C. L.; Ding, S.; Kuhn, P.; Rees, D. C. J. Mol. Biol. 2000, 296, 787.

(33) Sponer, J.; Burda, J. V.; Sabat, M.; Leszczynski, J.; Hobza, P. J. Phys. Chem. A 1998, 102, 5951.

(34) Sponer, J.; Sychrovsky, V.; Hobza, P.; Sponer, J. Phys. Chem. Chem. Phys. 2004, 6, 2772.

(35) Petrov, A. S.; Lamm, G.; Pack, G. R. J. Phys. Chem. B 2002, 106, 3294.

(36) Petrov, A. S.; Pack, G. R.; Lamm, G. J. Phys. Chem. B 2004, 108, 6072 .

(37) Baldwin, G. S.; Vipond, I. B.; Halford, S. E. Biochemistry 1995, 34,705 .

(38) Møller, C.; Plesset, M. S. Phys. Rev. 1934, 46, 618.

(39) Jansen, H. B.; Ross, P. Chem. Phys. Lett. 1969, 3, 140. 
(40) Boys, S. B.; Bernardi, F. Mol. Phys. 1970, 19, 553.

(41) Glendening, E. D.; Streitwieser, A. J. Chem. Phys. 1993, 100, 2900

(42) Glendening, E. D. J. Am. Chem. Soc. 1996, 118, 2473. 17152

(43) Schenter, G. K.; Glendening, E. D. J. Phys. Chem. 1996, 100,

(44) GaussView 3.09; Gaussian, Inc.: Pittsbourgh, PA, 2005.

(45) Roothan, C. C. J. Rev. Mod. Phys. 1951, 23, 69.

(46) Roothan, C. C. J. Rev. Mod. Phys. 1960, 32, 179.

(47) Pulay, P. Mol. Phys. 1969, 17, 197.

(48) Hehre, W. J.; Radom, L.; Schleyer, P. V.; Pople, J. A. Molecular Orbital Theory; Wiley: New York, 1986.

(49) Clark, T.; Chandrasekhar, J.; Spitznagel, G. W.; Schleyer, P. V. Comput. Chem. 1983, 4.

(50) Frisch, M. J.; Pople, J. A.; Binkley, J. J. Chem. Phys. 1984, 80, 3265 .

(51) Krishnan, R.; Binkley, J. S.; Seeger, R.; Pople, J. A. J. Chem. Phys. 1980, 72, 650

(52) Becke, A. D. Phys. Rev. A 1988, 38, 3098.

(53) Becke, A. D. J. Chem. Phys. 1993, 98, 5648.

(54) Lee, C.; Yang, W.; Parr, R. G. Phys. Rev. B 1988, 37, 785

(55) Vosko, S. H.; Wilk, L.; Nusair, M. 1980, 58, 1200.

(56) McLean, A. D.; Chandler, G. S. J. Chem. Phys. 1980, 72, 5639.

(57) Schäfer, A.; Horn, H.; Ahlrichs, R. J. Chem. Phys. 1992, 97, 2571.

(58) Hurley, M. M.; Pacios, L. F.; Christiansen, P. A. J. Chem. Phys.

1986, 84,6840

(59) Hariharan, P. C.; Pople, J. A. Theor. Chim. Acta. 1973, 28, 213.

(60) Francl, M. M.; Petro, W. J.; Hehre, W. J.; Binkley, J. S.; Gordon,

M. S.; DeFrees, D. J.; Pople, J. A. J. Chem. Phys. 1982, 77, 3654.

(61) Rassolov, V.; Pople, J. A.; Ratner, M.; Windus, T. L. J. Chem. Phys. 1998, 109, 1223.

(62) Frisch, M. J.; Trucks, G. W.; Schlegel, H. B.; Scuseria, G. E.; Robb, M. A.; Cheeseman, J. R.; Montgomery, J. A., Jr.; Vreven, T.; Kudin, K. N.; Burant, J. C.; Millam, J. M.; Iyengar, S. S.; Tomasi, J.; Barone, V.; Mennucci, B.; Cossi, M.; Scalmani, G.; Rega, N.; Petersson, G. A.; Nakatsuji, H.; Hada, M.; Ehara, M.; Toyota, K.; Fukuda, R.; Hasegawa, J.;
Ishida, M.; Nakajima, T.; Honda, Y.; Kitao, O.; Nakai, H.; Klene, M.; Li, X.; Knox, J. E.; Hratchian, H. P.; Cross, J. B.; Bakken, V.; Adamo, C.; Jaramillo, J.; Gomperts, R.; Stratmann, R. E.; Yazyev, O.; Austin, A. J.; Cammi, R.; Pomelli, C.; Ochterski, J. W.; Ayala, P. Y.; Morokuma, K.; Voth, G. A.; Salvador, P.; Dannenberg, J. J.; Zakrzewski, V. G.; Dapprich, S.; Daniels, A. D.; Strain, M. C.; Farkas, O.; Malick, D. K.; Rabuck, A. D.; Raghavachari, K.; Foresman, J. B.; Ortiz, J. V.; Cui, Q.; Baboul, A. G.; Clifford, S.; Cioslowski, J.; Stefanov, B. B.; Liu, G.; Liashenko, A.; Piskorz, P.; Komaromi, I.; Martin, R. L.; Fox, D. J.; Keith, T.; Al-Laham, M. A.; Peng, C. Y.; Nanayakkara, A.; Challacombe, M.; Gill, P. M. W.; Johnson, B.; Chen, W.; Wong, M. W.; Gonzalez, C.; Pople, J. A. Gaussian 03, revision C.02; Gaussian, Inc.: Wallingford, CT, 2004.

(63) Dunning, T. H., Jr. J. Chem. Phys. 1989, 90, 1007.

(64) Balabanov, N. B.; Peterson, K. A. J. Chem. Phys. 2005, 123, 064107.

(65) Weinhold, F.; Landis, C. R. Chem. Educ.: Res. Pract. 2001, 2, 91.

(66) Glendening, E. D.; Badenhoop, J. K.; Reed, A. E.; Carpenter, J. E.; Bohmann, J. A.; Morales, C. M.; Weinhold., F. NBO 5.0; Theoretical Chemistry Institute, University of Wisconsin: Madison, 2001.

(67) Gordon, M. S.; Schmidt, M. W. In Theory and Applications of Computational Chemistry, The First Forty Years; Dykstra, C. E., Frenking, G., Kim, K. S., Scuseria, G. E., Eds.; Elsevier: Amsterdam 2005; pp 1167.

(68) Schmidt, M. W.; Baldridge, K. K.; Boatz, J. A.; Elbert, S. T.; Gordon, M. S.; Jensen, J. J.; Koseki, S.; Matsunaga, N.; Nguyen, K. A.; Su, S.; Windus, T. L.; Dupuis, M.; Montgomery, J. A. J. Comput. Chem. 1993, 14, 1347.

(69) Miertus, S.; Scrocco, E.; Tomasi, J. Chem. Phys. 1981, 55, 117.

(70) Miertus, S.; Tomasi, J. Chem. Phys. 1982, 65, 239.

(71) Glusker, J. P. Adv. Prot. Chem. 1991, 42, 1.

(72) Dudev, T.; Cowan, J. A.; Linn, C. J. Am. Chem. Soc. 1999, 121, 7665 .

(73) Lamm, G.; Pack, G. R. J. Phys. Chem. B 1997, 101, 959.

(74) Sam, M. D.; Horton, N. C.; Nissan, T. A.; Perona, J. J. J. Mol. Biol. 2001, 306, 851 . 